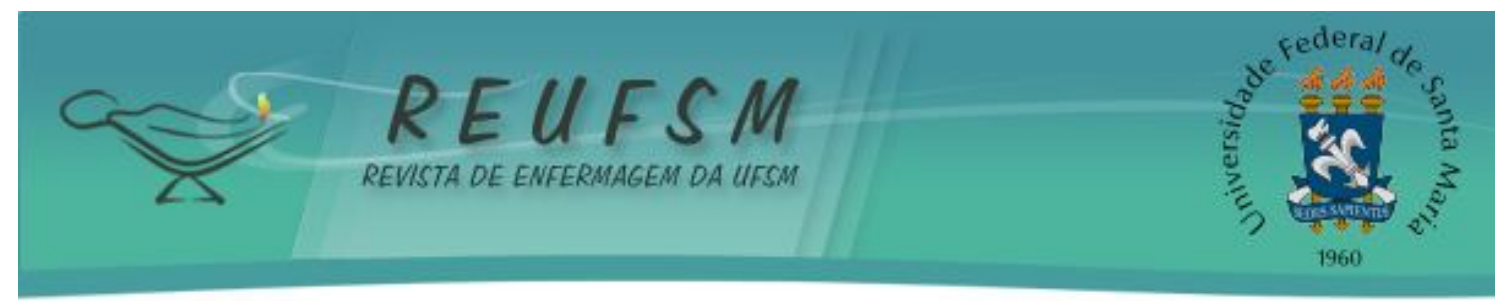

ARTIGO ORIGINAL

\title{
O OLHAR DAS EQUIPES DE REFERÊNCIA SOBRE O TRABALHO REALIZADO PELO APOIO MATRICIAL
}

THE LOOK REFERENCE OF THE TEAMS ON THE WORK DONE BY MAT RIX SUPPORT

LA MIRADA DE LOS EQUIPOS DE REFERENCIA EN EL TRABAJ O REALIZADO POR EL APOYO MAT RICIAL

Fábio Mello da Rosa ${ }^{1}$

Teresinha Heck Weiller ${ }^{2}$

Ana Paula Wilke François ${ }^{3}$

Liara Saldanha Brites ${ }^{4}$

Daiane Silveira ${ }^{5}$

Liane Beatriz Righi ${ }^{6}$

RESUMO: O artigo busca apresentar a experiência dos residentes da primeira turma do Programa de Residência Multiprofissional Integrada em Sistema Público de Saúde/ Universidade Federal de Santa Maria a partir do trabalho realizado pelos apoiadores matriciais em saúde da família sob a ótica dos profissionais que integram as equipes de referência da Estratégia de saúde da Família. Trata-se de um estudo descritivo, exploratório, de abordagem qualitativa, realizado de dezembro de 2010 a março de 2011, em um município do interior do Rio Grande do Sul. A coleta de dados da pesquisa foi realizada a partir de entrevistas semi-estruturadas, revelando que em dois anos de implantação do um programa de residência muito há que caminhar-se no sentido da construção de pactos cotidianos entre ensino e o serviço, tendo o diálogo como ferramenta e tecnologia na construção de proj etos terapêuticos que respondam as necessidades dos usuários.

Descritores: Saúde da família; Atenção primária à saúde; Sistema de saúde.

ABSTRACT: The article aims to show residents the experience of the first group of Multidisciplinary Residency Program in Integrated Public Health System / University of Santa Maria from the work performed by matrix supporters in family health from the perspective of professionals within teams reference of the Family health Strategy. It is a descriptive, exploratory qualitative approach, carried out from December 2010 to March 2011, a municipality in the interior of Rio Grande do Sul The data collection survey was conducted from semi-structured interviews, revealing that in two years of implementation of a residency program there is much that is walking towards the construction of everyday pacts between teaching and service, with dialogue as a tool and technology in the development of therapeutic projects that meet the needs of users.

Descriptors: Family health; Primary health care; Health systems.

\footnotetext{
1 Enfermeiro. Especialista em Sistema Público de Saúde. E-mail: enfmello07@yahoo.com.br.

2 Enfermeira. Doutora em Enfermagem. Professora adjunta do departamento de Enfermagem e da Residência Multiprofissional em Saúde da Universidade Federal de Santa Maria (UFSM). Membro do Grupo Cuidado, Saúde e Enfermagem. Coordenadora do Núcleo de Estudos em Saúde Coletiva. do CCS (UFSM). E-mail: weiller2@hotmail.com.

3 Psicóloga. Especialista em Sistema Público de Saúde. E-mail: anawfrançois@gmail.com.

4 Fonoaudiól oga. Especialista em Sistema Público de Saúde. E-mail: liarabrites@yahoo.com.br.

5 Fisioterapeuta. Especialista em Sistema Público de Saúde. E-mail: daianefisioufsm@yahoo.com.br.

${ }^{6}$ Enfermeira. Doutorada em Saúde Coletiva. Professora adjunta do departamento de Enfermagem da CESNORS Centro de Educação Superior do Norte Rio Grande do Sul, Campus Palmeira das Missões - Universidade Federal de Santa Maria - UFSM. E-mail: lianerighi@gmail.com.
} 


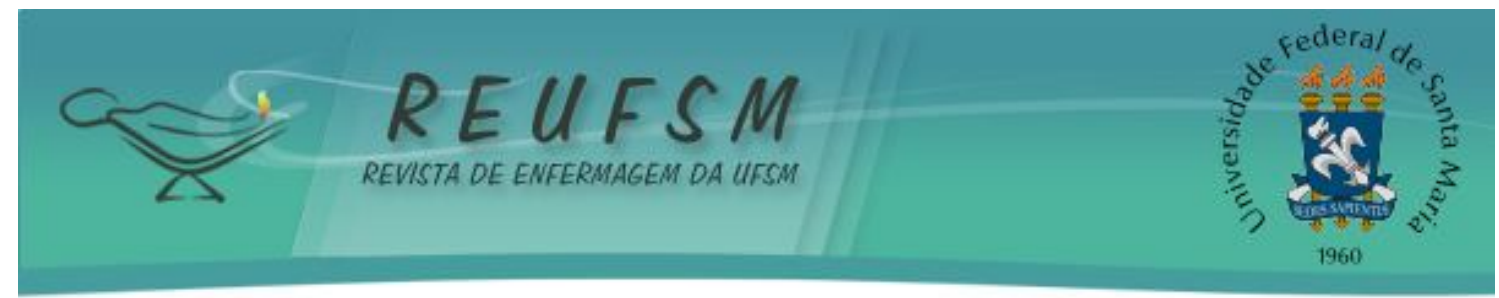

RESUMEN: El artículo tiene como objetivo mostrar la experiencia de los residentes del primer grupo del Programa de Residencia Multiprofesional Integrada en Sistema Público de Salud/Universidad Federal de Santa Maria a partir del trabajo realizado por los apoyadores matriciales en salud de la familia a través de la óptica de los profesionales que integran los equipos de referencia de la Estrategia de Salud Familiar. Además se trata de un estudio descriptivo, exploratorio, de abordaje cualitativo, realizado de diciembre de 2010 hasta marzo de 2011, en una ciudad del interior del Rio Grande del Sur. La colecta de datos de la pesquisa fue realizada a partir de entrevistas semiestructuradas, revelando que en dos años de aplicación de un programa de residencia tiene mucho que caminar hacia construcción de pactos cotidianos entre la enseñanza y el servicios, el diálogo como una herramienta y la tecnología en desarrollo de los proyectos terapéuticos que respondan las necesidades de los usuarios.

Descriptores: Salud familiar; Atención primaria de salud; Sistemas de salud.

\section{INTRODUÇÃO}

Inúmeros debates ocorreram em nível nacional para que se pudesse precisar um conceito de saúde que respondesse de forma adequada às necessidades presentes no Brasil no final do século XX. Nesse cenário, a 8a Conferência Nacional de Saúde desempenhou papel determinante, à medida que encaminhou a discussão teórica e ideológica dos conceitos de saúde, os quais vão ser incorporados na constituição do Sistema Único de Saúde (SUS). ${ }^{1}$ Dentre os avanços apontados situa-se o acesso universal e igualitário às ações e serviços de caráter público, formado por uma rede de serviços regionalizada, hierarquizada e descentralizada, com direção única em cada esfera de governo,com a participação dos usuários na busca de melhorar a qualidade da atenção à saúde prestada aos cidadãos brasileiros. ${ }^{1}$

Várias foram as tentativas no sentido de construção de instrumentos que viabilizassem a imediata tranforformação dos princípios legais em ações. Entretanto, frente 0 contexto de dificuldades encontradas pelo gestor federal para alteração do modelo assistencial vigente, foi lançado em 1994, o Programa de Saúde da Família (PSF). ${ }^{2}$ Assume esse, a tarefa de reorganizar as práticas assistenciais com bases em critérios que ultrapassassem o modelo tradicional de assistência, orientado na cura de doença. As necessidades de intervenções práticas de cuidados presentes nos territórios passaram a exigir das equipes de saúde, a superação de práticas individuais centradas em ações curativas, biomédicas, demandando intervenções multiprofissionais, interdisciplinares e intersetoriais.

Nesse cenário, nenhuma especialidade, de modo isolado poderá assegurar a integralidade da atenção. Para tal, faz-se necessário a existência de novos processos de trabalho, de bases interdisciplinares, que tem nas Equipes de Referência (ER) e no Apoio Matricial (AM), os dispositivos metodológicos e operacionais para essa mudança. ${ }^{3}$

Para o Ministério da Saúde (MS), Núcleo de Apoio à Saúde da Família (NASF) ${ }^{4}$, configura-se no espaço de práticas das ER e AM. Preconiza a constituição de equipes com diferentes núcleos de conhecimento atuando em conjunto com os profissionais das ER das ESF, compartilhando e apoiando as práticas em saúde nos territórios sob responsabilidade das mesmas. Tal composição deve ser definida pelos próprios gestores municipais e as equipes de ESF, mediante critérios de prioridades identificadas a partir das necessidades locais e da disponibilidade de profissionais e não se constitui porta de entrada do sistema para os usuários, mas sim de apoio às equipes de Saúde da Família. ${ }^{4}$

O Apoio matricial (AM) e a Equipe de referência (ER) são dispositivos operativos e filosóficos que sustentam a prática da clínica de forma ampliada, constitui-se na interface da formação de vínculo entre equipes e usuários produzindo a responsabilização clínica e sanitária. Possibilitam, ainda, a identificação de risco e vulnerabilidade presentes nos territórios, a construção de autonomias e a definição de proj etos terapêuticos singulares viabilizando o trabalho em equipe. ${ }^{3,5,6}$ 


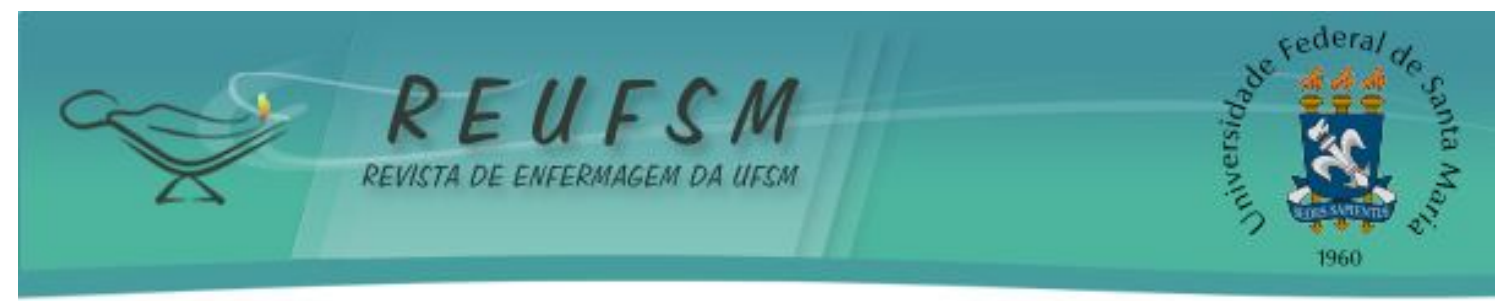

Desta forma uma ER é composta por médico, enfermeiro, técnico de enfermagem e agentes comunitários (equipe básica) que se vinculam a um número de usuários ou famílias definidas a partir de critérios demográficos, epidemiológicos, vinculados a uma ESF. A ER passa a responsabilizar-se pelos usuários do seu território, acompanhando-os ao longo do tempo nos aspectos que envolvem as questões de saúde e de doenças. Na construção de vínculo e na integralidade da atenção dos usuários sob-responsabilidade da ER, um número significativo de casos passam a exigir a intervenção de outros núcleos de conhecimentos. Nesse momento entra em cena os conhecimentos, em geral especializados, organizados sob a forma de AM. ${ }^{3}$

O AM of erece ao mesmo tempo retaguarda assistencial e suporte técnico-pedagógico às ER. Sua efetivação depende da construção compartilhada de diretrizes clínicas e sanitárias entre os componentes de uma ER e os especialistas que trabalham como AM. ${ }^{3}$ No caso em estudo, 0 AM foi constituído pelos seguintes núcleos profissionais: nutricionista, fisioterapeuta, fonoaudiólogo, psicólogo, terapeuta ocupacional e assistente social.

A partir de junho de 2009, os temas de AM e ER passaram a ser objetos de construção e reflexão na implantação do Programa de Residência Multiprofissional Integrada em Sistema Público de Saúde (PRMISPS/UFSM), uma vez que este objetiva qualificar profissionais da saúde recém egressos da universidade para trabalharem no SUS, cuja proposta pedagógica procura desenvolver metodologias de trabalho pautadas em práticas que buscam a integralidade das ações de saúde. ${ }^{7}$

Este estudo busca descrever a compreensão das Equipes de Referência (ER) a cerca do trabal ho desenvolvido pelos residentes na condição de Apoiadores Matriciais (AM).

\section{MÉTODO}

0 presente estudo é um produto do projeto intitulado "Apoio matricial em Saúde da Família: ações desenvolvidas e sinalização de caminhos para a organização de critérios e metodologias de trabalho na Residência Multiprofissional Integrada em Sistema Público de Saúde/ UFSM". Trata-se de um estudo descritivo, exploratório, de abordagem qualitativa, realizado entre dezembro de 2010 a março de 2011 em um município do interior do Rio Grande do Sul.

A coleta de dados foi realizada a partir de entrevistas semi-estruturadas. Os dados das entrevistas foram registrados em instrumento próprio pelos pesquisadores, audiogravados e está sob-responsabilidade do coordenador da pesquisa. Os dados das entrevistas foram tratados através da modalidade Análise Temática. ${ }^{8}$

Como critério de inclusão para o estudo foi considerado o fato de o profissional estar atuando no momento da coleta de dados em uma das três Unidades de Estratégia de Saúde da Família (USF) em que os residentes desenvolveram suas ações de $A M$ e que aceitaram participar mediante assinatura do Termo de Consentimento Livre Esclarecido.

Participaram da coleta de dados 38 entrevistados das Equipes de Referência (ER) com o seguinte perfil: a) Agentes Comunitários de Saúde (ACS): 26 (vinte e seis) concursados, carga horária de 40 (quarenta) horas semanais cada e predomínio de grau de escolaridade em nível médio; b) Enfermeiros do Serviço - 03 (três) concursados, carga horária de 40 (quarenta) horas semanais cada, sendo destes 02 (dois) com especialização em Saúde Coletiva e 01 (um) com mestrado; c) Enfermeiros residentes: 03 (três) com carga horária de práticas em serviço de 40 (quarenta) horas semanais cada, sendo 01 (um) com especialização em Saúde Coletiva/ Saúde da Família; d) Médicos: 03 (três) concursados, 02 (dois) destes, com carga horária de 40 (quarenta) horas semanais e 01 (um) com 30 (trinta) horas semanais, sendo 01 (um) Clínico Geral, 01 (um) Pediatra e 01 (um) Especialista em Saúde Coletiva; e) Cirurgião-dentista do serviço: 01 (um) concursado, com carga horária de 40 (quarenta) horas semanais e especialista em Saúde Coletiva; f) Cirurgião-dentista residente: 01 (um) com carga horária de práticas em serviço de 40 (quarenta) horas semanais, 


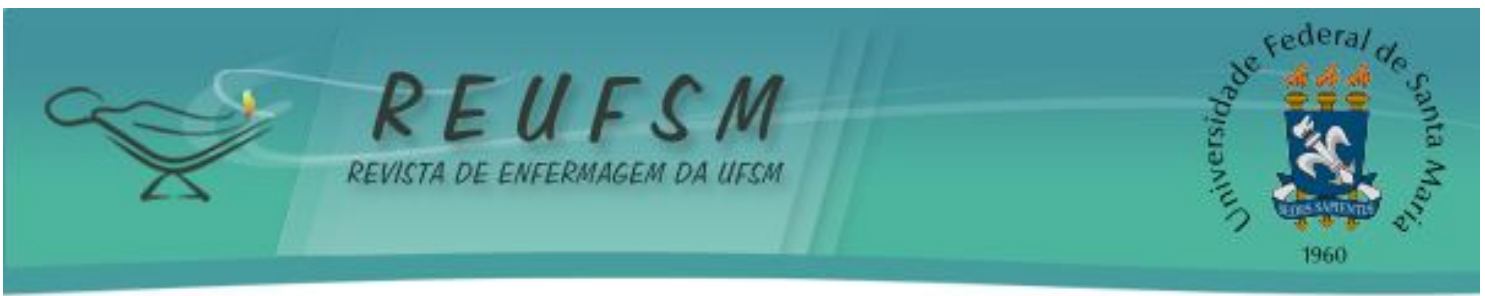

especialista em Saúde Coletiva e mestre em Odontologia e Saúde Coletiva; g) Técnico em Enfermagem: 01 (um) concursado, com carga horária de 40 (quarenta) horas semanais

A pesquisa observou as orientações da Resolução CNS 196/96, ${ }^{9}$ executada após a aprovação do Comitê de Ética em Pesquisa (CEP) da Universidade Federal de Santa Maria (UFSM), sob no CAAE 0313. 0.243.000-10.

\section{RESULTADOS}

Os dados que emergiram da pesquisa foram agrupados em dois temas principais, a saber, Equipe de Referência (ER) e Apoio Matricial (AM).

\section{Equipe de Referência (ER)}

Quando inquirido sobre o entendimento que dispunham sobre ER, foi possível identificar que um conjunto dos trabalhadores das USF detinham conhecimentos suficientes sobre ER e a função.

Os enfermeiros associam a ER à equipe mínima proposta pelo Ministério da Saúde - MS que atuam junto as ESF. Identificam os profissionais que a compõe, bem como, relatam a forma como a mesma atua.

É a equipe mínima que trabal ha em uma Unidade de Saúde da Família, médico, cirurgião-dentista, enfermeiros, técnicos de enfermagem, ACS, entre outros. (ENF1)

É aquele profissional que está mais fixo ou mais presente, que percebe o que é necessário no trabalho. Aquele que faz a referência para planejamento, execução, discussão de ações.(ENF2)

Os Cirurgiões-Dentistas (CDs) identificam a ER como sendo aquela que trabalha na USF composta por profissionais com formação superior (médico, enfermeiro, dentista), trabalhadores de nível médio e elementar, bem como os trabalhadores de serviços gerais.

É a equipe que trabalha na unidade. (CDs1)

Acho que é a equipe mínima da SF, são os recursos humanos que trabal ham constantemente nas unidades. (CDs2)

Dentre os médicos, apenas 01 (um) manifestou conhecer conceitualmente ER, relacionando-a com o serviço de saúde mais próximo da casa do usuário. Entretanto, não soube informar quais os profissionais que integram a equipe, uma vez que, não se reconhece como integrante de uma ER, aquela da região mais próxima da casa, (MÉD1). Os demais profissionais manifestaram tratar-se do atendimento secundário especializado, a partir do referencial do modelo de atenção centrado na modalidade de referência e contra referência aos serviços de saúde:

$\mathrm{Na}$ saúde pública as equipes de referência tem atendimento secundário especializado, como endocrinologia, traumatologia, entre outros. Remete ao sistema de referência e contra referência. (MÉD2)

Para os ACSs, a ER.

Refere-se a alguma coisa em que as pessoas podem identificar 0 profissional, o local para onde podem ser encaminhadas. (ACS1) 


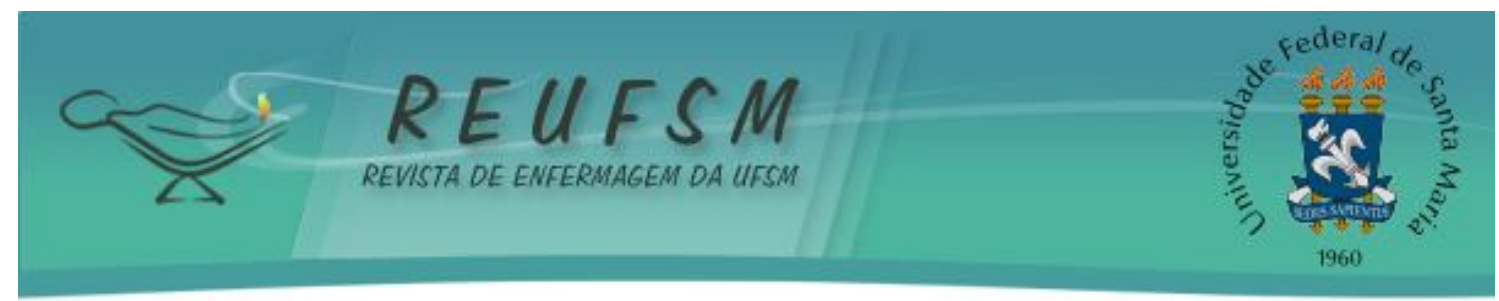

É a equipe onde tu levas os problemas e tens tua referência e contrareferência. (ACS2)

Tu tens um retorno, tu levas e sabes com quem tu vais falar. (ACS3)

Não vem a ser a equipe do posto? É aquela que trabalha no posto, a que os ACS faziam parte. Somos a referência, porque tu conheces a comunidade e tu moras lá, está sempre ali. No posto é fácil atender e ir embora, mesmo que queiras, não dá tempo de saber tudo daquela pessoa. (ACS4)

Manifestam reconhecerem-se como integrantes da equipe, entretanto, apontam a falta de profissionais em suas unidades como limitadora para o trabalho, uma vez que identificam o papel desempenhado por uma ER em um dado território.

E possível, mas leva um tempo para ser formada, é o médico, enfermeiro, técnico de enfermagem, ACS. (ACS5)

o papel que a ER tem é de dar apoio, um suporte, uma salvação que passa a suprir a nossa falta. È formada por enfermeiro, médico, agente comunitário. (ACS6)

Dentre os trabalhadores de nível médio foi possível entrevistar apenas um técnico de enfermagem tendo em vista ser esse o único em exercício no período da pesquisa. Identificou a ER como sendo a responsável por acolher o usuário, ser a referência no serviço de saúde:

É a equipe completa, disposta a atender o paciente que vem buscar cuidados na unidade. Ele sabe que vai chegar e vai encontrar. Então, isso se torna uma referência pra ele. (TEC.ENF1)

A pesquisa revelou o desconhecimento de boa parte dos trabalhadores das USF sobre ER, uma vez que, mesmo trabalhando em unidades de ESF, não reconhecem o seu trabalho como integrante de uma ER, uma vez que associam a ação de referência à especialidade médica, sustentado no modelo biomédico, hegemônico no campo da saúde.

Outro aspecto identificado diz respeito ao fato de existir ACS que não se reconhecem e não reconhecem a sua equipe como de referência.

Não sei te responder, não sei se tem isso aqui. (ACS7)

Já ouvi, mas não sei. O nome diz que é uma referência para nós, mas não sei bem. (ACS8)

Não ouvi falar. (ACS9)

Dentre os enfermeiros, apenas um não soube definir ER, associando o seu trabalho a uma equipe que acolhe os casos mais complexos. Para esse profissional, ER é vista como referência especializada.

Equipe onde possa encaminhar os casos, onde a Unidade de Saúde da Família não consegue dar conta. Por exemplo: câncer de mama. (ENF3)

\section{Apoio matricial - AM}

Quando entrevistados os enfermeiros, esses por sua vez, manifestam conhecer do que trata o AM e como esse operou no cotidiano das ERs. Porém, não souberam identificar quais os profissionais que integram as equipes do AM, tão pouco identificaram ou fizeram 


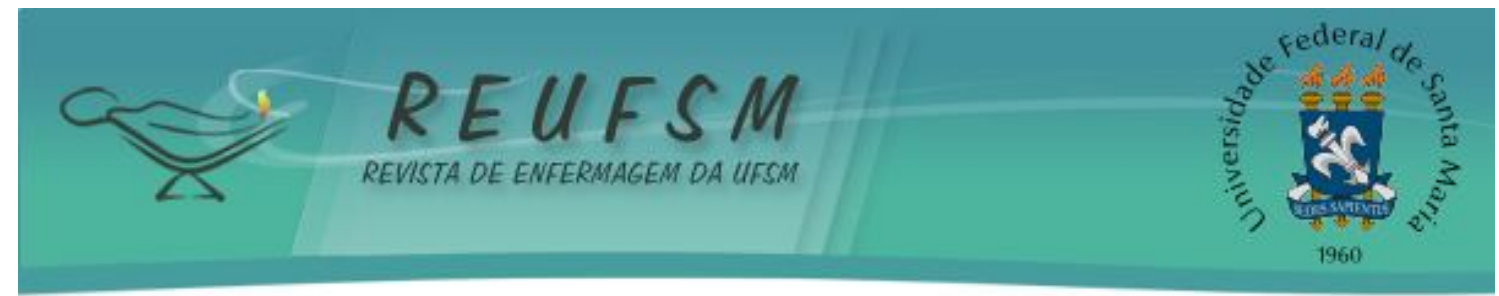

referência ao trabalho desencadeado por residentes que desempenharam essa tarefa em sua unidade por dois anos junto às unidades que atuam:

São profissionais que dão apoio/ suporte à ER quando há necessidade, como grupos e casos compl exos que extrapolam o conhecimento da ER. (ENF1) Suporte para a ER, e pessoas do serviço especializado que atua na unidade e na comunidade, trabalham de forma preventiva. (ENF2)

Para alguns, o trabalho do AM reduz a capacitação das equipes. Relacionam o trabalho que é proposto pelos Centros de Atenção Psicossocial (CAPS), percussor do AM que surge na saúde mental, a partir da perspectiva da Reforma Psiquiátrica:

São diferentes categorias profissionais com conhecimentos diferentes para capacitar a equipe básica. (ENF3)

No CAPS a gente encaminha pra USF ou pro matriciamento. Só que a gente não tem o suporte, grupos para fazer o apoio e que vão precisar de atendimento especializado. (ENF4)

Outro aspecto observado é que os profissionais mesmo reconhecendo a forma como trabalham os apoiadores matriciais, reiteram que, sem 0 atendimento clínico especializado o cuidado ao usuário não é integral, pois só o tratamento preventivo não resolve sozinho o problema dos usuários e da Unidade:

Seriam os profissionais que a gente não tem na equipe e viriam pra auxiliar a ER. Mas tem casos que não tem o que discutir que 0 especialista também precisa intervir que só a discussão não dá conta e a gente precisa de especialistas. (ENF5)

Entre os profissionais Médicos, apenas 01(um) demonstrou conhecimento sobre a forma como é organizado o trabalho de AM, ampliando o conceito de matriciamento, ao contrário dos demais que atribuem à ação dos apoiadores matriciais apenas ao atendimento individual de usuários:

São profissionais que não são da Equipe Mínima, como fonoaudiólogo, psicólogo, e nutricionista, e que dão acompanhamento nos casos necessários e nos grupos. (MÉD1)

Um dos cirurgiões-dentistas demonstrou ter conhecimento sobre o tema, referindo $A M$ a um conjunto de conhecimento complementar às $E R$, entretanto, não identifica quais os profissionais que integram ou deveriam integrar uma equipe de AM e reconhece a existência de uma subdivisão do trabalho, um assistencial e outro gerencial:

É aquele apoio que é prestado por um ou mais profissional, é o apoio de conhecimento complementar daquele da ER. Pode ser assistencial ou gerencial. (CDs1)

Os ACSs por sua vez demonstram limitações conceituais quando buscaram definir o AM, todavia, identificam os profissionais que compõe a equipe de AM.

Entendo, mas não sei explicar. Não é o trabalho que vocês fazem? Tem psicólogo, nutricionista, fisioterapeuta, um conjunto todo. (ACS1) 


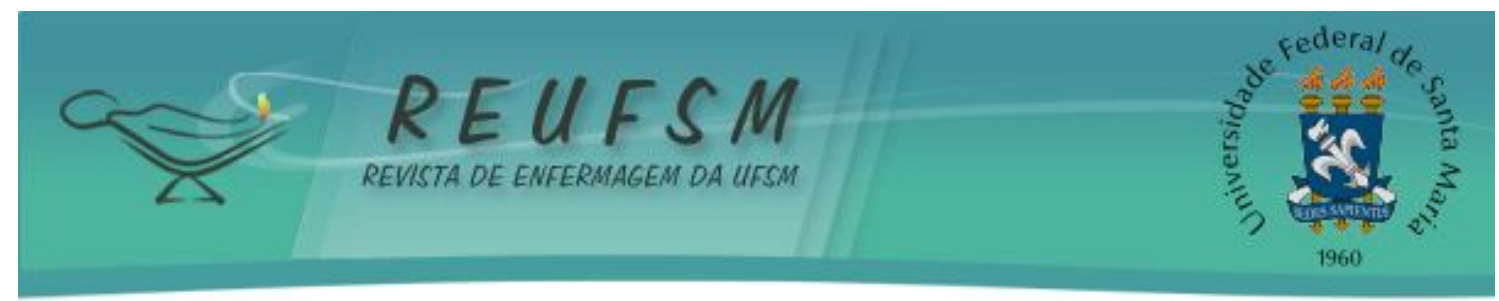

É uma equipe extra que vem apoiar a equipe local nas Visitas Domiciliares (VDs), uma saída pra gente se apoiar e conseguir apoio lá fora, pra mim, isso seria tudo de bom! (ACS2)

Foi possível identificar manifestações que remetem à compreensão de um conceito ampliado do AM, ao sinalizar ser esse o apoio dado ao conjunto de trabalhadores que compõem a ER e que o AM amplia a ação desenvolvida pelo ACS:

Residentes que prestam apoio para os ACS. (ACS3)

Acho importante, mas do que adianta ter apoio se vocês (residentes), se não tem nem espaço físico e falta ACS. (ACS4)

Os profissionais da residência, vários profissionais da área da saúde nos ajudando. (ACS5)

Acho que é esse trabalho junto, multidisciplinar, esse apoio para a família, porque ai não vem só o enfermeiro, os demais, contribuem para se ver a pessoa como um todo. (ACS6)

Vem uma equipe para ficar a disposição para atendimento e apoiando aquele lugar nos casos trazidos. (ACS7)

É o complemento em uma equipe, e é muito importante. (ACS8)

Por outro lado, a pesquisa revela que dentre os ACS existem dificuldades de compreender o papel desempenhado pelos residentes apoiadores matriciais:

Iriam dar um apoio, referência e contra referência, mas isso ficou só no papel. Faz anos que falam em AM. (ACS9)

Nada, até hoje [...]Tentaram me explicar, mas não consigo entender, visualizar esse apoio. Eu fico com vergonha, mas é uma realidade. (ACS10)

\section{DISCUSSÃO}

No universo estudado foi possível identificar limitações conceituais relacionadas à ER e ao AM, uma vez que são esses "ao mesmo tempo, arranjos organizacionais e uma metodologia para a gestão do trabalho em saúde, obj etivando ampliar as possibilidades de realizar-se clínica ampliada e integração dialógica entre distintas especialidades e profissões" . ${ }^{4}$

Identificou-se também que existem trabalhadores que não se reconhecem como integrantes de uma ER, especialmente os médicos que em suas manifestações sinalizam não se reconhecer como trabalhadores. Observou-se que predominam nas práticas dos trabalhadores de saúde concepções teóricas que reforçam o modelo biomédico de cuidado e atenção "caracterizado pela explicação unicausal da doença, pelo biologicismo, fragmentação, mecanicismo, recuperação e reabilitação, tecnicismo, especialização. A unicausalidade pressupõe o reconhecimento do agente etiológico, é este que deverá ser identificado e combatido". ${ }^{4}$

0 estudo revela, a forma como a assistência é organizada nas ESF onde os residentes desenvolveram o dispositivo do apoio matricial, dado que a assistência é organizada a partir da demanda espontânea, por fichas. Outro fato que corrobora na definição do modelo vigente nas ESF é o fato de que não ocorria reuniões de equipes, bem como a troca constante dos trabalhadores auxiliou na manutenção da desestruturação da rede dificultando a consolidação do AM, dado verificado no desconhecimento do potencial do trabalho dos residentes apoiadores matriciais que permaneceram nos territórios por dois anos.

Percebeu-se na fala das equipes que a integração entre residentes e profissionais do serviço deu-se de forma insuficiente e esses manifestaram ter conhecido o trabalho do 


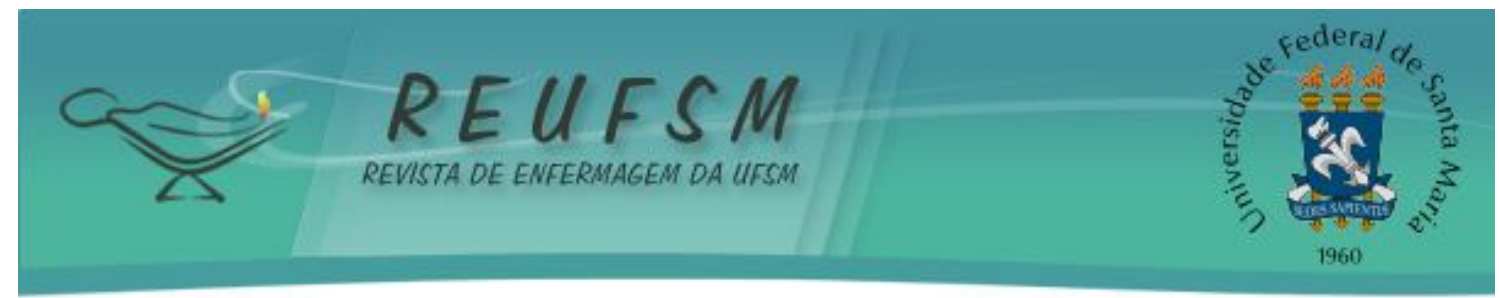

AM ao acompanhar os residentes nas atividades cotidianas. Outros que não entraram em contato com as práticas desenvolvidas pelos residentes nos territórios revelaram desconhecimento sobre o trabalho.

Esse contexto reafirma uma prática fragmentada do trabalho, uma vez que os profissionais não conseguiram entre si uma articulação para a gestão do cuidado, ficando os usuários reféns da falta de informações, conversas, trocas de casos entre a equipe, afetando diretamente seu processo terapêutico. Fato que corrobora para a não abordagem integral da atenção e do cuidado e faz refletir que, embora se pense em novas abordagens na perspectiva da integralidade, ainda há uma construção fragmentada do olhar e do atendimento ao usuário nas unidades. 0 apoio matricial e equipe de referência articulam nesse sentido de reunir conhecimentos e trabalhá-los de forma ampla e horizontal. ${ }^{10}$

A insatisfação de alguns e o entendimento limitado de outros justifica-se, pois, em nenhum momento foi mencionada a gestão municipal como incentivadora das práticas de AM em Saúde da Família, tão pouco foi referido suporte teórico em programas de educação permanente para instrumentalização desses profissionais, embora o MS preconize por meio do Pacto de Gestão, ${ }^{11}$ a política de educação permanente para os trabalhadores do SUS.

\section{CONSIDERAÇÕES FINAIS}

Assim ao refletir sobre os resultados deste estudo evidencia-se que o conjunto de trabalhadores que integram as equipes de referência nas unidades de estratégia de saúde da família, no município estudado, revela limitações sobre o tema. Pois, ao serem convidados a refletir sobre a ação desenvolvida por residentes, na condição de apoiadores matriciais nesses territórios, tiveram dificuldades para identificar esta ação. Este dado revela que o movimento feito por um conjunto de atores (residentes, gestores, usuários, trabalhadores da rede municipal e da universidade) para consolidação de um programa de formação de trabalhadores para o SUS, na modalidade de residência multiprofissional, carece de pactuação contínua.

Esse desafio por si só já se torna grandioso, à medida que enfrenta cotidianamente um movimento de fragilidade e de descontinuidade da rede de atenção à saúde pública no município estudado. Torna-se importante reconhecer que os processos, sejam eles de formação de trabalhadores para o cuidado, seja do envolvimento dos trabalhadores e gestores do SUS para o redesenho de novas redes de cuidados, conectadas, resolutivas, universais é um processo permanente.

A pesquisa revelou que em dois anos de implementação do Programa de Residência Multiprofissional na Atenção Básica, há necessidade de pactos cotidianos entre a instituição de ensino, gestão e trabalhadores para a proposição de metodologias de trabalho que garantam a integralidade das ações em saúde. Nesse contexto, o dispositivo do apoio matricial assume relevância para desencadear processos de mudanças no modelo de produção de cuidado em saúde. Dessa forma, o estudo aponta que o diálogo contínuo constitui-se em ferramenta e tecnologia necessário para efetivar as necessidades dos usuários sob responsabilidade das equipes de referência amparadas por equipes matriciais. Por fim, a co-responsabilização dos profissionais e gestores da rede municipal na formação de trabalhadores para o SUS, no caso, de residentes para atenção básica é uma meta a ser buscada nos próximos anos.

\section{REFERÊNCIAS}

1. Brasil. Lei Orgânica 8080, de 19 de setembro de 1990. Ministério da Saúde. Dispõe sobre as condições para a promoção, proteção e recuperação da saúde, a organização e o funcionamento dos serviços correspondentes e dá outras providências. Diário Oficial da União. Brasília, 19 set. 1990. Disponível em: «ttp:// portal. saude.gov. br/ portal/ arquivos/ pdf/ LEl8080. pdf>Acesso em 01 abr. 2011. 


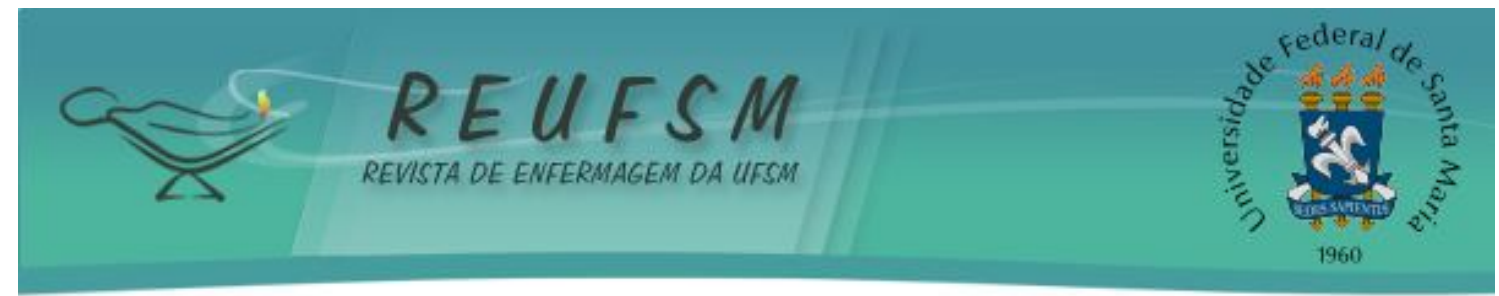

2. Brasil. Ministério da Saúde. Programa Saúde da Família. Brasília: Ministério da Saúde, 2000. 44 p.

3. Campos GWS; Domitti AC. Apoio Matricial e Equipe de Referência: uma metodologia para gestão do trabalho interdisciplinar em saúde. Cad Saúde Pública [periódico na internet].2007; [acesso em 12 jun 2011] 23(2):399-407. Disponível em: http:/ / www. scielosp. org/ pdf/ csp/ v23n2/ 16. pdf.

4. Brasil. Ministério da Saúde. Caderno de Atenção Básica de Diretrizes do NASF- Núcleo de apoio a Saúde da Família. Brasília: Ministério da Saúde, 2009. 160 p.

5. Coelho, IB. Formas de pensar e organizar o sistema de saúde: os modelos assistenciais em saúde. In: Campos \& Guerrero. Campos, GWS. Guerrero, AVP. (orgs). Manual de Práticas da Atenção Básica: saúde ampliada e compartilhada. São Paulo: Hucitec, 2008.

6. Merhy, EE. Chakkour, M. Em busca de ferramentas analisadoras das tecnologias em saúde: a informação e o dia-a-dia de um serviço, interrogando e gerindo trabalho em saúde. In: Merhy, EE; Onocko, R. (Orgs.) Agir em saúde: um desafio para o público. São Paulo: Hucitec, 1997, p. 113-150. (Saúde em Debate n. 108 - Série didática n. 6).

7. Universidade Federal de Santa Maria. Centro de Ciências da Saúde. Projeto do Programa de Residência Multiprofissional Integrada em Sistemas Público de Saúde. Santa Maria, 2009.

8. Minayo, MCS. O desafio do conhecimento: pesquisa qualitativa em saúde. 12. ed. São Paulo: Hucitec, 2010.

9. Brasil. Ministério da Saúde. Conselho Nacional de Saúde. Resolução no 196, de 10 de outubro de 1996 - aprova diretrizes e normas regulamentadoras de pesquisas envolvendo seres humanos. Brasília: Ministério da Saúde; 1996.

10. Campo GWS, Domitti A C. Apoio matricial e equipe de referência: uma metodologia para gestão do trabalho interdisciplinar em saúde. Cad saúde pública [periódico na Internet]. 2007 Feb [acesso em 12 mai 2011] ; 23(2): 399-407. Disponível em: http:/ / www. scielosp.org/ scielo. php?script=sci arttext\&pid=S0102-

311X2007000200016\&lng=en. http:/ / dx. doi. org/ 10.1590/ S0102-311X2007000200016.

11. Brasil. Ministério da Saúde. Portaria n. 399/GM, de 22 de fevereiro de 2006. Divulga o pacto pela saúde 2006 - consolidação do SUS e aprova as diretrizes operacionais do referido pacto. Diário Oficial da União, Brasília, 23 fev. 2006. Seção 1, p. 43-51.

Data de recebimento: 18/07/2011

Data de aceite: 10/09/2011

Autor Responsável: Fábio Mello da Rosa

Endereço: Visconde de Pelotas, 1899. Ap 402, bairro Nossa Senhora de Fátima, Santa Maria, RS.

CEP: $97015-140$.

E-mail: enfmello07@yahoo.com.br 